\title{
Reflexiones en torno al megalitismo de Europa occidental
}

\author{
ANA M. ${ }^{\text {a MUÑOZ }}{ }^{\star}$
}

A pesar de que hace ya más de veinte años que se propuso, y aceptó, el hecho de que el megalitismo se inició en Europa occidental antes que en ningún otro lugar del mundo, y que las cámaras abovedadas de piedra podían remontarse a comienzos del IV milenio a.C. ${ }^{1}$ en las síntesis sobre Neolítico español, no suelen incluirse las manifestaciones megalíticas, a pesar de su importancia para acercarnos al mundo social y religioso de las poblaciones prehistóricas de esa época y como testimonio del profundo proceso de cambio experimentado.

En el I Congreso del Neolítico de la Península lbérica, celebrado en Gavá en marzo de 1995, ya se incluyeron, muy acertadamente, algunos aspectos relacionados con el megalitismo: ajuares dolménicos de la provincia de Burgos, y referencias a enterramientos megalíticos, al tratar el ritual funerario. Aunque no fuera mucho, sí fue al menos una llamada a incluir el tema del megalitismo cuando se trata del Neolítico, ya que, como voy a intentar poner de manifiesto, el megalitismo es una parte muy importante del Neolítico pleno de Europa occidental.

En la actualidad, una vez rechazadas las teorías difusionistas sobre el origen mediterráneo oriental del megalitismo de Europa occidental, sobre todo a partir de la valoración de sus altas cronologías por Renfrew, las dataciones absolutas - sin calibrar- para sus inicios, remontan el mega-

* Catedrática de Prehistoria. UNED.

RENFREW, C., Before civilization. The radiocarbon revolution and Prehistoric Europe. Penguin Books, Suffolk, 1973. ACTAS da 1.a Mesa Redonda sobre O Neolítico e o Calcolítico em Portugal. Porto 1979, Trabalhos do Grupo de Estudos Arqueológicos do Porto. ACTAS de la Mesa redonda sobre Megalitismo Peninsular. Madrid, Asociación Española de Amigos de la Arqueología, madrid 1984. ARRIBAS, A., y MolinA, F.: «Estado actual de la investigación del megalitismo en la Península Ibérica". Scripta Praehistórica, F. Jordá Oblata. Salamanca 1984, pp. 63-112. AA.VV.: El megalitismo en la Península Ibérica. Ministerio de Cultura, Madrid, 1987. 
litismo a tiempos neolíticos de comienzos del IV milenio a.C., y parece que todo el mundo admite su origen local. Sin embargo, como en otras muchas manifestaciones culturales de la Prehistoria, siguen sin aclararse las causas de su aparición.

Colin Renfrew relacionaba el incremento de población experimentado en Europa durante los inicios del Neolítico con la aparición de las primeras tumbas megalíticas en la fachada atlántica (Bretaña y Portugal) a mediados del $\mathrm{V}$ milenio. Los megalitos serían indicadores, que reafirmaban los derechos sobre la explotación de un determinado territorio por parte de pequeños grupos de población unidos por relaciones de parentesco, lo que llama "sociedades segmentarias". El esfuerzo común además, ayudaba a cohesionar internamente al grupo local, y el monumento advertía a posibles competidores por el territorio.

Para R. Chapman, la disposición de los muertos en un espacio formalizado, sea en megalitos o no, supone la expresión de los derechos de un grupo corporativo sobre el acceso a los recursos básicos y la necesidad de expresarlos se plasmaría en construcciones visibles "megalíticas". Son varios los autores que parecen coincidir en la consideración del monumento megalítico como una especie de reafirmación territorial. Los sepulcros megalíticos aparecen tanto aislados como formando extensas necrópolis (Gor, Los Millares, Reguengos en la Península Ibérica), y es habitual su situación en lugares que destacan en el conjunto de un paisaje determinado.

La pregunta a responder sería ¿porqué era tan necesario, precisamente en éste momento - comienzos del IV milenio a.C. - el reafirmar de forma tan evidente el dominio de un territorio, y vincularlo precisamente al ritual funerario? La interpretación histórica en principio parece fácilmente deducible, sobre todo si comparamos la situación con circunstancias semejantes repetidas hasta nuestros días: los "derechos históricos" sobre un territorio, transmitido por unos antepasados a sus sucesores, que aparecen adscritos a la propia tierra más allá de la muerte. El monumento funerario megalítico vinculaba el lugar a un linaje determinado.

Pero, sobre todo, hay que destacar que el comienzo del megalitismo en algunos lugares de Europa occidental, se remonta al Neolítico. Se ha roto por tanto la antigua relación del megalitismo y otros sistemas de enterramiento colectivo con los poblados fortificados tipo Millares o Vilanova de San Pedro y los comienzos de la metalurgia, a mediados del III milenio, en el periodo que llamamos Calcolítico. En realidad, en 1943, G. y V. Leisner ya habían puesto de manifiesto el hecho de que algunos megalitos del sur de Portugal y de la provincia de Huelva, situados precisamente en zonas 
con recursos mineros de cobre, no mostraban ninguna relación con la actividad metalúrgica ${ }^{2}$. Tal es el caso del sepulcro de San Bartolomé de la Torre ${ }^{3}$ y de la necrópolis de El Pozuelo, donde no se encontró metal entre los ajuares funerarios, por lo que según Cerdán y Leisner, la necrópolis sería anterior al descubrimiento de la metalurgia ${ }^{4}$

En el Alentejo, donde hay numerosas minas de cobre, el metal es escasísimo en las tumbas megalíticas. En la negrópolis de Reguengos de Monsaraz, entre el material inventariado por los Leisner, correspondiente a 134 megalitos, el único objeto de metal era argárico ${ }^{5}$. Parece que en Portugal este empieza a usarse cuando las tumbas de cúpula ya estaban en uso. En el Alentejo, en la zona de Serra de Grándola, con las ricas minas de Castro Verde, entre otras, el metal que aparece en las tumbas megalíticas, fechadas por TL a mediados del IV milenio a.C., es escaso y parece corresponder al Calcolítico final. En Extremadura en cambio, el metal abunda más, pero las sepulturas pueden ser también más tardías.

Actualmente sabemos que el megalitismo se inicia en Europa Occidental y concretamente en la Península Ibérica, por lo menos unos quinientos años antes de que aparezca el uso del cobre y, aunque el megalitismo se prolongue hasta época del vaso campaniforme, no siempre se relaciona con la metalurgia. Esto no quiere decir que en época Calcolítica el megalitismo, y en general las necrópolis y formas de enterramiento múltiple, no tengan una gran dispersión y máximo apogeo, a lo largo del III milenio, pero esto es propio del proceso normal de cambio de las distintas sociedades prehistóricas en las que se encuadra. Por ello es de gran importancia conocer el contexto originario en que se produce la aparición del megalitismo y tratar de buscar el motivo, la causa de la creación nada menos que de la primera gran arquitectura europea por las comunidades prehistóricas indígenas.

Al tratar de buscar el contexto originario, lo primero que destaca de forma patente, es que hay un fuerte contraste entre las zonas en las que el Neolítico se implantó muy pronto (VI-V milenio), -bien sean las medite-

2 LeISNer, G. y V. Die Megalithgräber der Iberischen Halbinsel (Der Süden) Berlín 1943, p. 256.

Leisner, G. y V., y Pérez NúNez, E.: “Dolmen de cúpula de San Bartolomé de la Torre». Intormes y Memorias de la Comisaria General de Excavaciones Arqueológicas 26, Madrid, 1952, pp. 41-47.

4 CeRdán, C., y LeISNER, G. y V.: "Los sepulcros megalíticos de Huelva". Informes y memorias de la Comisaria general de Excavaciones Arqueologicas 26, Madrid 1952, pp. 14-15.

LEISNER, $G$ y $V$ : Antas do concelho de Reguengos de Monsaraz. Instituto para a Alta Cultura, Lisboa 1951. 
rráneas de la cerámica impresa y cardial o las centroeuropeas de la cerámica de bandas - y las que recibieron o aceptaron más tarde las formas de vida neolíticas, las áreas más periféricas del NO de Francia, las islas Británicas o la zona atlántica de nuestra península.

Se ha sugerido que la aparición de los cairns, sepulturas de cámara cubiertas con bóveda de piedra, dentro de un túmulo también de piedra, en el noroeste de Francia, muy a comienzos del IV milenio, se debió a una mezcla de la tecnología de las gentes de la LBK (cerámica de bandas) con las tradiciones funerarias indígenas, que pueden documentarse en lugares costeros como Téviec y Hoèdic, aunque en realidad la LBK no aparece en estos lugares, sino más bien la de tipo Chassey.

En los concheros del Muge, en su confluencia con el Tajo, en Portugal, donde se recolectaban moluscos de agua dulce y salada, pescaban y cazaban, la abundancia de recursos permitía sustentar poblaciones en asentamientos semipermanentes o permanentes a finales del VI milenio a.C. (Moita do Sebastiâo), en el V (Cabeço da Amoreira) y en el V-IV (Cabeço da Arruda). Este grupo, forma parte de un fenómeno muy amplio que se observa en el área costera atlántica y cantábrica de la época. El gran número de sepulturas individuales que se han podido estudiar en estos asentamientos -en Moita do Sebastiao unas 34-confirmarían el carácter semipermanente de estos establecimientos.

En Bretaña, también parecen confirmarse asentamientos semipermanentes o permanentes como los de Téviec y Hoëdic, fechados hacia el 4000 a.C., con tumbas individuales y pequeñas tumbas colectivas en cámaras rudimentarias, 0 en tumbas delimitadas por piedras y cuernas de asta. Las primeras tumbas de cámara abovedadas bretonas, son las de Barnenez y Kerkado, fechadas a comienzos del IV milenio a.C., lo que sugeriría la importancia de las tradiciones y prácticas indígenas, según $\mathrm{J}$. L'Helgouach.

Portugal también ofrece construcciones megalíticas (antas) muy antiguas, que se remontan a comienzos de IV milenio a.C., contemporáneas en parte de los concheros de Muge: Outeiro de Ante 3 (Porto), fechada por C 14 en $3830 \pm 80$ a.C., y Outeiro de Gregos (Porto) en $3280 \pm 75$ a.C.

En conjunto, el contexto parece revelar una continuidad en el sustrato de población, tanto en Bretaña como en Portugal, que queda reflejado sobre todo en la tecnología lítica de tradición mesolítica, con técnica de tipo laminar y tendencia al microlitismo (trapecios y triángulos). El sustrato en el que aparece el megalitismo, de acuerdo con las dataciones absolutas de que disponemos, muestra poblaciones con continuidad de las formas de vida cazadora recolectora en el IV milenio. 
Las formas de vida neolítica en los primeros tiempos del megalitismo, es posible que fueran de carácter mixto, agrícola y ganadera, aunque en muchos casos no hay documentación suficiente. Los indicios de antropización del paisaje, con descenso del bosque, lo mismo podría deberse al uso del suelo para cultivos que para pastos o para ambos. En Irlanda del norte, donde se observa un gran descenso del olmo, se ha pensado que podía deberse al clareo del bosque para facilitar el desarrollo de los grandes mamíferos, como el ciervo rojo, cuyos restos, juntos con los de salmón, muestran una caza-pesca especializada, que permitía establecimientos semiestables. La localización de los megalitos en algunos casos, teniendo en cuenta las condiciones ambientales, parecen revelar una actividad con preponderancia pastoril, lo que en muchos casos explicaria la falta de restos de asentamientos estables.

La actividad fundamentalmente agrícola, ya desde el $\mathrm{V}$ milenio, parece poder relacionarse más con el tipo de enterramiento individual en fosa, como es el caso de las necrópolis neolíticas con cerámica de bandas en el centro de Europa, o en las propias cuevas de habitación en el neolítico mediterráneo, tanto antiguo de cerámicas impresas, como reciente de cerámicas lisas. O en necrópolis como las de sepulcros de fosa de Cataluña, Francia suroriental y Suiza, en zonas especialmente aptas para la agricultura. Este tipo de necrópolis con fosas del Neolítico pleno, en ocasiones llegan a excavar verdaderas estructuras sepulcrales, que, en condiciones particularmente aptas, forman hipogeos de enterramiento múltiple, que presentan un desarrollo extraordinario en lugares como Cerdeña (cultura de Ozieri). En Cátaluña, contemporáneamente a los sepulcros de fosa, en el IV milenio, empiezan a aparecer las construcciones megalíticas en la zona del Ampurdán oriental.

Hay hipogeos o "cuevas artificiales» en la costa atlántica próxima al estuario del Tajo, en zonas de gran riqueza agrícola, que parecen iniciarse en el IV milenio, contemporáneamente al "neolítico de Pavia» -de tradición mesolítica - y a los megalitos alentejanos, caracterizados por las plaquetas de pizarra grabadas. Se trata en realidad un Neolítico cronológicamente avanzado, que se ha localizado estratigráficamente en varios asentamientos, como el de Penedo de Lexim ${ }^{6}$, el de Parede ${ }^{7}$, e

\footnotetext{
6 Arnaud, J.M. "O povoado fortificado neo-eneolítico do Penedo de Lexim (Mafra)», $O$ Arqueólogo Portugués, serie 3, 5, Lisboa 1971, pp. 97-131.

7 Cunha Serrao, E. "A estaçao pré-histórica de Parede. Documentos inéditos sobre estatigrafía e estructuras (campanha de 1956)". O Arqueologo Portugués, serie 4, 1, Lisboa 1983, pp. 119-148.
} 
incluso en los sondeos de Savory en Vila Nova de Saô Pedro ${ }^{8}$ y más recientemente, en Leceia.

Todo esto parece indicar la contemporaneidad de dos formas de enterramiento, la tradicional neolítica inicialmente de sepulturas en fosa, en necrópolis o en cuevas, que posteriormente parece asimilar el ritual colectivo (hipogeos) y en megalitos, que desde el principio tiene el carácter colectivo. Ya en el III milenio, continúa el uso de hipogeos, se extienden los megalitos por amplias áreas, a veces en necrópolis relacionadas con grandes centros de población en lugares especialmente aptos para una rentable actividad agrícola, suficiente para una población estable y numerosa. (En España, Los Millares, Valencina de la Concepción, La Pijotilla). En este contexto, aparece un nuevo tipo de sepulcro, construido en mampostería de piedra, a veces combinada con grandes losas. Son los sepulcros de corredor con cámara circular cubierta con una falsa cúpula, protegida por un túmulo artificial. La gran necrópolis de Los Millares ofrecía el prototipo, que Siret relacionó con los tholoi micénicos. Hoy sabemos que son más antiguos los occidentales. Los de Los Millares de mediados del III milenio. Pero ya a comienzos del IV se construía con esta técnica en Bretaña. En general están en conexión con grandes zonas agrícolas (Antequera, campiña del Guadalquivir, de Huelva y Algarve) en ocasiones sustituyen a antiguos hipogeos (Praia das Maças) o se inspiran en ellos (La Pijotilla), pero los hipogeos siguen activos en la rica campiña cordobesa y sevillana (Gilena), donde sus ricos ajuares compiten con los más destacados de las sepulturas construidas en mampostería.

Las respuestas que me atrevería a dar a las dos preguntas propuestas al principio, sobre el porqué surge el megalitismo y porqué su carácter funerario, serían las siguientes. El megalitismo surge como una necesidad de proteger y conservar las tierras de caza, pesca y recolección, vinculadas a un grupo. Bien sea para preservar la antigua actividad frente al avance colonizador de gentes agricultoras, o más bien para reafirmar sus derechos anteriores al comenzar nuevas estrategias de explotación agrícola y pastoril. Esto sería especialmente necesario para delimitar el aprovechamiento de pastos por los distintos grupos. Los límites de pastizales siempre han creado problemas. Los tenemos documentados desde la Edad Media con el sistema de mugas, hasta nuestros días (zona de pastoreo vasco-navarro a ambos lados del Pirineo). De todas formas, en el análisis reciente del megalitismo gallego, hay una tendencia a vincularlo

- SAVORY, H.N.: «A section throug the innermost rempart at the Chalcolithic Castro of Vila Nova de Saó Pedro, Santarem (1959)». Jornadas Arqueológicas. Lisboa 1970. 
más a actividades agrícolas que de pastoreo, y algo parecido parece apuntarse en la zona vascocantábrica.

En segundo lugar, la necesidad de vincular el territorio a un grupo de tradición cazadora, con una organización social de tipo clánico, exigía reafirmar la identidad del grupo sobre el individuo, en un lugar de enterramiento común, monumento o necrópolis. Las poblaciones neolíticas ya asentadas, habrían perdido este concepto gentilicio, en favor de la unidad familiar vinculada a la casa más que a la tierra, pero que más tarde evolucionaría hacia nuevas formas, separando la ciudad de los vivos de la de los muertos (necrópolis). Por alguna razón el concepto clánico o de comunidad más amplia que la familia natural, se extendió posteriormente, durante el III milenio - seguramente debido a la gran mobilidad a que dio lugar un pastoreo extensivo- incluso a grandes comunidades agrícolas. Recientemente, ${ }^{9}$ se ha señalado la presencia de cuentas de collar de variscita en dólmenes de la provincia de Burgos, concretamente en el Dolmen de Fuentepecina II. Sedano, fechado por C 14 en $3220 \pm 100$ y $3425 \pm 45$, ambas b.c., y en el Dolmen de Cubillejo de Lara, fechable entre el IV-III milenio b.c., de posible procedencia de las minas de Can Tintoré (Gavá, Barcelona), lo que indicaría unas tempranas relaciones, en el Neolítico de la segunda mitad del IV milenio, entre las gentes de los sepulcros de fosa y el occidente de la Meseta.

Este esquema de organización social, que he denominado clánico, debió de resultar insuficiente para dirigir grandes explotaciones con agrupaciones demográficas importantes. Por ello se sustituyó con una vuelta a los sistemas de tradición agrícola y sobre todo a un individualismo diferenciado, en que las familias ostentaban distintas categorías. Así, la organización social en la Europa prehistórica del II milenio, revela en general un sistema de tipo aristocrático, en vez del poder centralizado al que llegaron los grandes núcleos agrícolas del Próximo Oriente, desembocando en un sistema urbano.

Me atrevería a decir que la estructura socioeconómica que representa el megalitismo, con su tradición cazadora recolectora, se adaptaba bien a grupos pastoriles, pero no a explotaciones de tipo agricola más complejas, con actividades diversificadas, que, increíblemente, retrocedieron a un sistema social que correspondía a formas de vida más simples. Esta sería la causa de que los grandes centros campesinos europeos no evolucionaran

9 Rojo, M.A., “Adornos de calaita en los ajuares dolménicos de la provincia de Burgos: Apuntes sobre su composición y procedencia». Actes I Congrés del Neolític a la Península lbèrica, Vol. 1, Museo de Gavà 1966, pp. 239-250. 
hacia una verdadera vida urbana hasta el I milenio e incluso hasta la Baja edad Media.

El megalitismo es además, en gran medida, una forma de arquitectura funeraria, con fuerte carga social y religiosa. Inicialmente he señalado su importancia social para reafirmar la presencia real del grupo, pero es importante intentar acercarse al mundo religioso funerario como expresión del carácter del grupo y sus relaciones. Por ello es muy interesante destacar los grabados y pinturas de los megalitos de Bretaña, Irlanda, el occidente de nuestra Península, con temas fundamentalmente abstractos, -aunque algunos se hayan querido interpretar con objetos concretos-y estrechamente relacionados entre sí, sin duda debido al sustrato común "atlántico» del que derivan. Hay una gran diferencia entre estas representaciones abstractas, algunas muy repetitivas, y las de la "diosa madre", propia de las culturas neolíticas europeas y mediterráneas.

Más tarde, cuando las formas de sepulcros de enterramiento colectivo se asimilaron por otros grupos, se advierten claras diferenciaciones de riqueza en los ajuares, posibles símbolos de poder, y un curioso sincretismo entre las representaciones abstractas y antropomorfas, no siempre referidas a la supuesta "diosa madre" sino más bien al propio difunto. 
1. Megalitismo.

2. Cerámica de bandas

3. Neolítico mediterráneo

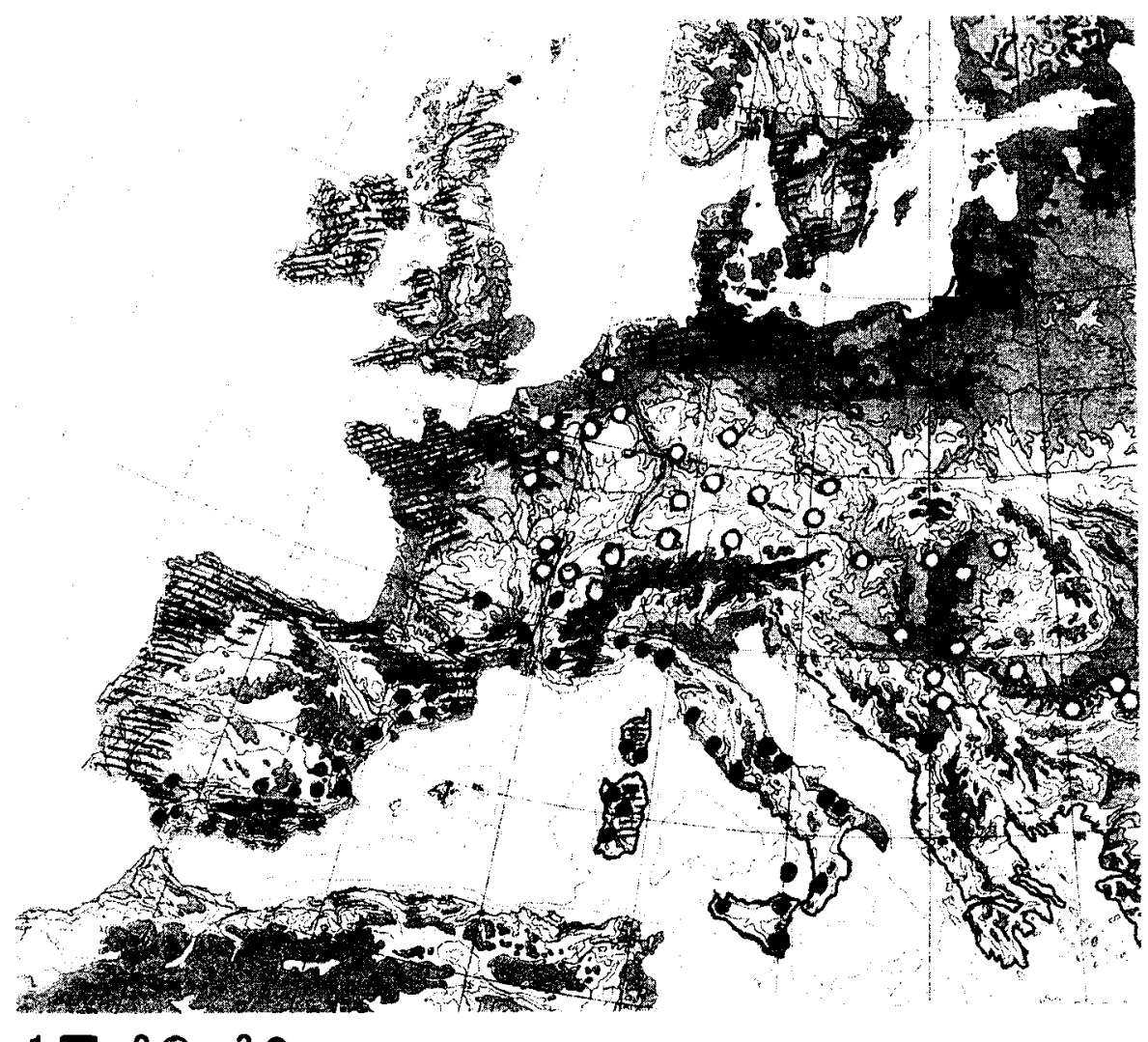

$1 \multimap 203$

Áreas de dispersión del Neolítico antiguo y del megalitismo por Europa. 